\title{
Performances da Pedagogia: uma narrativa estético-pedagógica
}

\section{Performances of Pedagogy: an aesthetic-pedagogical narrative}

\author{
Lucia Maria Salgado dos Santos Lombardi*
}

\begin{abstract}
RESUMO
$\mathrm{O}$ artigo analisa questões que têm emergido de experimentações feitas no cruzamento da formação de professores e da arte da performance no contexto de um curso de Pedagogia. A linguagem performática é abordada em suas dimensões expressiva e formativa, ampliando os horizontes das reflexões sobre as culturas escolares, as relações pedagógicas e as intencionalidades do ato educativo. Para construir o debate, a narrativa é estruturada de forma a revelar as etapas de trabalho de três iniciativas performativas, analisando-as.

Palavras-chave: Arte da Performance. Ensino de Arte. Pedagogia. Formação de Professores.
\end{abstract}

\begin{abstract}
The article analyzes questions that have emerged from the experiments carried out at the intersection of teacher training and performance art in the context of a Pedagogy course. The performance language is approached in its expressive and formative dimensions, broadening the horizons of reflections on school cultures, pedagogical relationships and the intentionalities of the educational act. In order to construct the debate the narrative is structured in order to reveal the stages of work of three performative initiatives, analyzing them.
\end{abstract}

Keywords: Performance Art. Art Teaching. Pedagogy. Teacher training.

* Universidade Federal de São Carlos. Sorocaba, São Paulo, Brasil. E-mail: lucialombardiufscar@gmail.com.http://orcid.org/0000-0001-6978-864X 


\section{Introdução}

Este texto apresenta experimentações com a arte da performance e as questões pedagógicas que surgem delas no contexto da formação inicial em Pedagogia. As propostas formativas ocorrem no âmbito da disciplina de "Metodologia e Prática do Ensino de Arte", na extensão universitária e em oficinas oferecidas em eventos científicos da universidade. São projetos do campo do ensino das artes que procuram responder à questão: qual a potência de ações performativas no território da formação de pedagogos?

Do corpo da proposta como um todo, seu coração é o questionamento das persistentes concepções tradicionalistas de educação, que pensam o papel da escola, os conteúdos, as metodologias e as relações professor-aluno limitadas às pedagogias da transmissão. A transmissão como método é uma das formas de se propiciar o conhecimento, mas não é a única e nem a melhor. Já a transmissão como valor, baseia-se em lógicas de controle, opressão e regulação burocrática da escola (OLIVEIRA-FORMOSINHO; KISHIMOTO; PINAZZA, 2007). E essas lógicas persistem. "Corta o coração" observar, ainda hoje, a tenacidade de professores ocupando papel autoritário, disciplinador e prescritor. Daí surge a ideia do emprego da performance na formação de pedagogos - "com o coração saindo pela boca"! - como pernas e braços que possibilitam exercícios participativos de fazer pedagogia, que realizam uma dialogia constante entre a intencionalidade do ato educativo e sua prossecução no contexto com os sujeitos, "porque estes são pensados como ativos, competentes e com direito a codefinir o itinerário do projeto de apropriação da cultura que chamamos educação" (OLIVEIRA-FORMOSINHO, 2007, p. 19)

Tenho abordado o ensino das artes como sendo relevante à formação de pedagogos tanto no sentido da formação cultural e artística em si e no preparo para o trabalho com as artes junto às diferentes infâncias, mas também como caminho de possível rompimento com antigos paradigmas no terreno da formação de professores, pautados em valores de simplificação da pessoa, de previsibilidade de conteúdos e de pobreza de interações entre educadores e educandos (LOMBARDI, 2011, 2015, 2015a).

A performance na formação docente tem como propósito provocar os estudantes a um debate sobre as vivências escolares ao longo de suas vidas abarcando, inclusive, seu atual contexto formativo na universidade, para que emerjam visões críticas sobre as culturas escolares e os modos de fazer pedagógico. Isto porque, almejo confrontar o monopólio da pedagogia da transmissão, reconstruindo os projetos educacionais (e não apenas fazendo um exercício de 
desocultação), atravessando o nível da retórica e de fato transformando a esfera praxiológica (OLIVEIRA-FORMOSINHO, 2007).

Para construir o debate sobre a experiência com a performance no curso de Licenciatura em Pedagogia, apresento a seguir uma narrativa estruturada de forma a revelar as etapas de trabalho de três iniciativas performativas - fases que aliam estudos do conceito e da história da performance com acesso à produção teórica sobre o tema, a apreciação de trabalhos de artistas nacionais e internacionais, bem como a criação e execução de intervenções - analisando-as. As iniciativas ressaltadas são: Decifra me ou devoro te; Menin@s; Fraturas/ Escuto Traumas de Escola.

O estudo se move entre março de 2013 e julho de 2017, observando os atos que tomaram o espaço urbano do campus Sorocaba da Universidade Federal de São Carlos, em perspectiva a um só tempo estética, pedagógica e também política. Política porque, além de realizar descrições e reflexões, o texto aborda a performance em sua capacidade de destacar a condição histórico-cultural da pessoa, a não neutralidade das concepções defendidas e a crença na educação como prática intrinsecamente democrática, da forma como Paro $(2002$, p. 17) explica: "Educar-se é, a esse respeito, um verbo reflexivo. O educando, a rigor, nunca é educado por alguém, mas sim educa-se pela mediação do educador. Aqui se identifica uma relação em que há sempre o consentimento livre do outro. Sem o consentimento livre do educando, não há educação."

\section{Etapas do trabalho: estudamos e refletimos. Performance vem sendo...}

Para realizar processos com a performance na formação de pedagogos, tenho iniciado os trabalhos com a apresentação do histórico e do conceito, oferecendo acesso a certo arcabouço teórico que possa aproximar futuros pedagogos desse tipo de arte. Tenho especial consideração pelas especificidades da formação desse profissional ao escolher as sugestões de leitura, sendo algumas: Renato Cohen (2002), Marcelo de Andrade Pereira (2010), Naira Ciotti, Gilberto Icle em artigos e em seus capítulos do livro de Marcelo Pereira (2013), Tania Alice (2013), Elyse Lamm Pineau (2010).

Sinto prazer em dialogar com a produção da $\operatorname{Prof}^{\mathrm{a}}$. $\mathrm{Dr}^{\mathrm{a}}$. Thaise Luciane Nardim (2013, 2014, 2015 a, 2015 b, 2015 c), do curso de Licenciatura em Artes - Teatro da Universidade Federal do Tocantins (UFT). Apesar da distância geográfica, somos aproximadas pelo Grupo de Pesquisa Arte na Pedagogia 
(GPAP) liderado pela Prof ${ }^{\mathrm{a}}$. Dra ${ }^{\mathrm{a}}$. Mirian Celeste Martins, que me permitiu conhecer cuidadosamente suas pesquisas dedicadas à arte contemporânea, numa acepção que abrange tanto as artes visuais quanto o teatro, assim como outras linguagens, investigando relações entre arte contemporânea, performance e educação. Thaise Nardim avizinha-se bastante da Pedagogia por ser artista da performance que consegue friccionar os fazeres artísticos nos pedagógicos, levando em consideração os múltiplos educadores que existem, preocupada em dialogar com professores em formação.

Existem variadas definições para a arte da performance nas literaturas internacional e nacional, entre as quais está a colocação de Alice (2013) de que a busca por uma definição essencialista do que "é" performance já seria uma maneira de pensar referente à modernidade em que a estética era delimitada e enquadrada por categorias fixas. A autora considera mais interessante pensar o que "vem sendo" performativo. Diante disso, define:

Interdisciplinar, transformadora, transgressiva, a performance, além de se cunhar como linguagem artística, apresenta-se, mais do que como uma disciplina artística, como uma indisciplina que amplia fronteiras, abre horizontes, rompendo com códigos representacionais preestabelecidos, afirmando-se como linguagem artística independente, não comercial e não comercializável, gerando consciência política e fomentando desejos de transformação social. (ALICE, 2013, p. 36)

Do ponto de vista das experiências com não artistas - estudantes de Pedagogia -, a performance se reafirma como uma possibilidade expressiva que articula diferentes modalidades de arte (teatro, dança, música, cinema, artes visuais, tecnologias), que permite o estabelecimento de relações diretas entre arte e vida cotidiana e que promove uma grande liberdade criativa, sem a obrigação de se delimitar contornos específicos do tipo de arte que se faz, sem cobranças relacionadas a virtuosismos ou a habilidades artísticas específicas.

Alice (2013) apresenta a performance como uma linguagem artística que não pode ser enquadrada por ser um emaranhado de diferentes linguagens, que se define propriamente por sua indefinição, que invade os espaços mais diversificados. Para Fabião (2009), a performance desafia definições, pois ativa dinâmicas paradoxais: trata-se da fundação de uma cena-não-cena equiparável ao teatro não representacional vislumbrado por Artaud.

Estudamos teoricamente a linguagem da performance não apenas para situá-la, mas porque a narração histórica dessa arte e suas análises não passam ao 
largo daquilo que ocorre no cenário urbano. Diz Fabião (2008, p. 238) que "cada performance é uma resposta momentânea para questões recorrentes." Então, além de ampliação de repertório que possibilite engendrar novas simbologias, estudar a literatura existente sobre o campo possibilita atravessar caminhos em direção ao entendimento dos anseios dos artistas que estão na rua.

\section{Etapas do trabalho: fruímos alguns, em meio a tantos que podem ser apreciados}

A fruição de trabalhos de performance e intervenção urbana objetiva aproximar os estudantes de outros referenciais estéticos bastante presentes na diversidade da contemporaneidade. Múltiplas influências contribuem para instigar futuros pedagogos à apreciação e à criação de uma arte que não poderá ser vendida, possuída, repetida. Admiramos artistas e coletivos que se colocam em situação de presença democrática nas ruas, travando possíveis encontros com o público flutuante, acidental, casual, não convocado - os transeuntes.

Citar nomes de artistas que tomam a cidade nunca será justo nem completo. Artistas solo, grupos e coletivos vão se somando a nossos repertórios a partir de estudos, de pesquisas, de visitas culturais e artísticas e do acaso. Do Brasil, apreciamos fotos e vídeos de produções de Eduardo Srur, Coletivo Mapa Xilográfico, Coletivo Pi, Desvio Coletivo, Ana Teixeira, Ernesto Ferro, Alexandre Órion, Mundano, Cambar Coletivo. Da Bélgica, Francis Allÿs. Da Inglaterra, Bansky. Iván Argote \& Pauline Bastard, da Colômbia e França. Marina Abramovic, da Sérvia. Dos Estados Unidos, Guerrilla Girls. Hector Zamora, México/Portugal.

A grande maioria dos estudantes do curso de Pedagogia que chegam à universidade, ainda hoje, vem de uma escola que exerceu imposições de se desenhar dentro da margem e colorir dentro das linhas, de atuar nos "teatrinhos" e "dancinhas" nas datas comemorativas e festas escolares, de ter como prêmio para bom comportamento ou bons trabalhos realizados, a chance de fazer um "desenho livre". Vêm da escola que avalia massivamente por meio de provas, com uma lógica de avaliação tradutora de uma sociedade condicionada pelas regras de mercado, dos êxitos e fracassos, produção e rendimentos, vencedores ou excluídos.

Apreciamos a arte da performance porque essa fruição provoca deslocamentos e estranhamentos imediatos sobre aquilo que se viu, se viveu e a que se foi submetido. São observados outros pontos de vista a respeito das questões de gênero, etnia, condições sociais, questões ambientais. A discussão corre di- 
retamente para os modos de vida presentes dentro e fora da instituição escolar e para as lógicas sustentadoras da práxis em sala de aula.

A performance surpreende, desoculta e desnaturaliza de pronto os hábitos aparentemente neutros que perpassam a realidade escolar e ocupam as salas de aula, trazendo meios de criticar a realidade vigente. $\mathrm{O}$ alimento das imagens é de tamanha força, que remexe a consciência sobre a necessidade de outras lógicas, que estranhem o mundo dado.

\section{Etapas do trabalho: acontece a ação artística}

"Durante a performance eu vi a imprevisibilidade 'comendo' nossos planos" Calíope Oliveira Corcovia

Após estudarmos e apreciarmos performance, muito comumente surge na juventude o desejo por se manifestar dessa maneira. Iniciam-se as rodas de conversa, as tempestades de ideias, que se ligam a momentos de práticas corporais e de criação. O processo culmina com os estudantes indo ao espaço urbano, não ficcional, não preparado previamente para apresentações artísticas, ao encontro de um público de "transeuntes como dramaturgia e elemento de composição" (ALICE, 2013). Performando, exercitam sua presença nos lugares da universidade que já conhecem, mas agora uma presença provocadora, carregada de outras simbologias e outros sentidos, recriando suas presenças.

\section{Três iniciativas performativas}

\section{Decifra me ou devoro te}

No campo do ensino de arte, a performance deixa de ser unicamente um conceito e uma forma artística, passando a representar uma possibilidade de estar em sala de aula. Em outubro de 2013, ofereci na semana científica do curso de Pedagogia um minicurso com duração de cinco dias denominado "Performance universitária: o que é verdadeiramente social na arte é a forma", que consistia em cinco encontros que almejavam impulsionar reflexões sobre as relações de poder e controle na universidade e criar uma intervenção urbana como tempo/ 
lugar de expressão poética dos pensamentos e sentimentos de seus participantes, por meio da linguagem performática cênica.

A inspiração para este trabalho surgiu das reflexões que emergiram sobre o ato pedagógico a partir da leitura de Pereira (2010, p. 151), que questiona: "De que maneira a recuperação da dimensão expressiva do ato pedagógico serve para desenvolver o pensamento e a prática educativa contemporânea?". A escuta de narrativas de professores-artistas em 2013 no âmbito de encontros que reuniam estudantes da pós-graduação em Arte no Instituto de Artes UNESP - Universidade Estadual Paulista na disciplina "Tópicos Especiais: arte, experiência e educação" e membros do grupo de pesquisa "Performatividades e Pedagogias", liderado pela Prof ${ }^{a}$. Dr". Carminda Mendes André, representou o incentivo final para a criação de uma ação como professora-provocadora (RACHEL, 2013): que provoca conflitos no sentido de desacomodar o processo de ensino aprendizagem, estimulando a discussão e o interesse por conhecimentos.

Estudantes inscritos para o minicurso, ao chegarem, me encontravam em pé diante da porta da sala de aula, vestida com roupas de dormir (camisola, chinelos), peruca descabelada, armação de óculos de alguma antiga professora, uma lousa pendurada do pescoço, giz e apagador na mão. Com o ideário da figura da professora como detentora privilegiada de conhecimento e com a escola como instituição preocupada em professar verdades, eu perguntava, com mau humor e aspereza: “o que é escola para você?" Entregando o giz na mão do estudante, apontava para a lousa em meu peito. Ele tinha que segurá-la e escrever nela a resposta. Em praticamente todos os casos, a pessoa já demonstrou tensão e a necessidade de acertar. Eu a lia com descaso, apagava rudemente, dizendo que a resposta estava errada (independente de qual fosse), mandava entrar e sentar em silêncio. Dentro da sala, as carteiras enfileiradas eram ocupadas conforme chegavam mais pessoas. Aquelas que já estavam lá, por vezes esboçaram vontade de rir ou conversar com alguém ao lado, para o que eu as repreendia. Repreendi de forma mais severa um grupo de três rapazes que estavam no corredor e não eram estudantes inscritos para o minicurso de performance, dizendo que era proibido usar celular na escola e que eu "mandaria chamar suas mães". Assustados me olharam e saíram de perto. Dentro da sala de aula, os participantes ameaçaram um riso nervoso por causa dessa ação, que reprimi com o olhar. Ao entrar na sala, iniciei tarefas-clichê de escola, tais como cópias da lousa, ditados e provas-surpresa. Todos me obedeciam em tudo, em silêncio, sem contestar. O clima de tensão era muito alto. Comecei a oferecer situações que possibilitassem o jogo, abrindo espaços para que os participantes desejassem dizer algo, contradizer, rir, perceber a caricatura, a farsa, o teatro. Nada, além de obediência. Uma hora depois, parei. Coloquei a música "Renascer" de Zizi Possi. Tirei da sacola um pote de álcool em gel e uma embalagem de algodão, colocando-os sobre a mesa, 
porque me serviam para tirar uma maquiagem vermelha forte que eu tinha sob os olhos. Diante deles tirei o figurino daquela que denominei "professora adormecida", por estar insensível ou entorpecida por sua atitude autoritária. Estando sem figurino e em adereços, usando minhas roupas usuais, desliguei a música e perguntei: "Pessoal, tudo bem? [PAUSA] O que aconteceu?"

Os participantes estavam em estado de choque. Bem aos poucos compreenderam que eu estava atuando. Diziam que não sabiam se eu era de fato "daquele jeito" e aquilo poderia ser uma aula "normal". Impressionada com essa reação, perguntei como eles poderiam pensar que aquilo fosse real, sendo que eu estava caracterizada de forma caricatural e visivelmente teatral. Do choque foram mudando para sensações de revolta e indignação com suas próprias reações como seres oprimidos, silenciados, dóceis, treinados por uma escola de tamanha eficiência nisto a que se propõe. Duas estudantes relataram que se sentiram mais ainda paralisadas quando coloquei o álcool sobre a mesa, porque durante suas infâncias passaram por uma mesma situação, tendo frequentado duas escolas diferentes de Sorocaba, em que se alguma menina viesse maquiada para a aula, a professora passava-lhe um pano com álcool no rosto. Ardia.

Seguimos com o debate no sentido de compreender as reações que a "plateia" teve diante de uma professora autoritária que faz uso de clichês do universo da sala de aula. Nos encontros subsequentes, trilhamos as etapas de trabalho descritas anteriormente no presente artigo e o grupo decidiu criar e performar aquela que foi denominada "Decifra me ou devoro te". Com gases sobre os rostos, expressando como se sentem machucados pela escola, bloqueamos a mesa de coffee break do evento no qual estávamos inseridos.

FIGURA 1 - PERFORMANCE "DECIFRA ME OU DEVORO TE”.
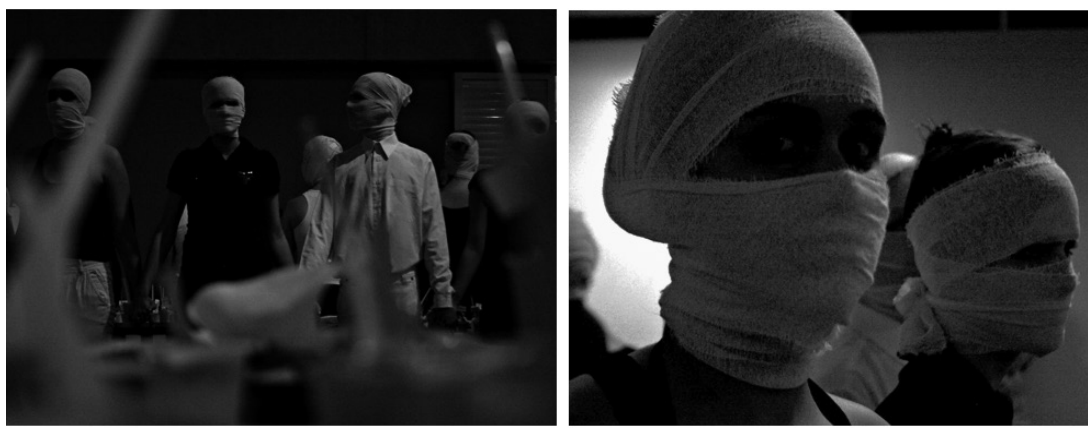

FONTE: Fotos de Tiago Francis. 


\section{Rafael Romeiro Doin, estudante do curso de Pedagogia e participante desse processo, relatou sobre esta experiência:}

Não imaginei o quanto a performance iria mexer comigo. Durante o processo fui deixando de olhar para fora e comecei a olhar para dentro $e$, com essa dinâmica, perceber pinceladas de sentimentos que em alguns momentos traziam alegrias e, em outros, medos adormecidos.

Poder ter um espaço onde se pode olhar para si e através desse contato criar algo que irá dialogar com o externo é um processo muito rico e cheio de significados que me levou a pensar em como eu me relaciono com o outro e comigo mesmo, refletindo diretamente como eu pretendo me relacionar no ambiente escolar e quais as formas de aprendizagem escolher para trabalhar com as crianças, sujeitos criativos e ativos nesse processo.

É impressionante como a relação de poder é algo que acontece na escola de forma quase imperceptível, passamos anos dentro da escola acreditando que poder é sinônimo de respeito e rigidez. Quando percebemos que existem outras formas de relação entre os sujeitos e buscamos trazê-las para nosso cotidiano, vamos percebendo como estamos envenenados dessa rigidez. Durante o processo da performance, fui entrando em contato com esse veneno e, a partir dali, comecei a trilhar um caminho que ainda não terminei, mas aos poucos estou trocando o poder que me foi mostrado dentro da escola por um olhar carinhoso, acolhedor, que busca aos poucos romper com esse poder estabelecido. E o poder que existe dentro da escola acaba aparecendo na universidade vestindo novas caras, porém, quando você enfrenta seus medos e põe a cara a tapa, assim como fiz durante a performance, sua percepção em relação ao poder preestabelecido também ganha novas caras.

Passei a perceber os momentos em que as relações aconteciam através do poder e procurei me posicionar de maneira contrária, ativamente me projetando no espaço da universidade.

Durante a performance percebi o quanto as pessoas precisavam daquele momento para expressar seus sentimentos, nos cobram muitas coisas externas e às vezes deixamos eles de lado. Quando deixamos de sentir, perdemos a vontade de reagir.

Necessitamos de momentos como esse para despertar nossos sentimentos, pretendo levar isso como um ensinamento e construir momentos dentro da instituição escolar que tragam para fora os sentimentos e, a partir disso, criar junto com os sujeitos envolvidos um novo espaço de relação. ${ }^{1}$

1 Rafael Romeiro Doin. Informação pessoal recebida por e-mail. Autorizada em seu uso por meio de assinatura de Consentimento Informado e Esclarecido. 
Fraturas. Escuto traumas de escola

FIGURA 2 - IMAGENS DAS PERFORMANCES FRATURAS E ESCUTO TRAUMAS DE ESCOLA.

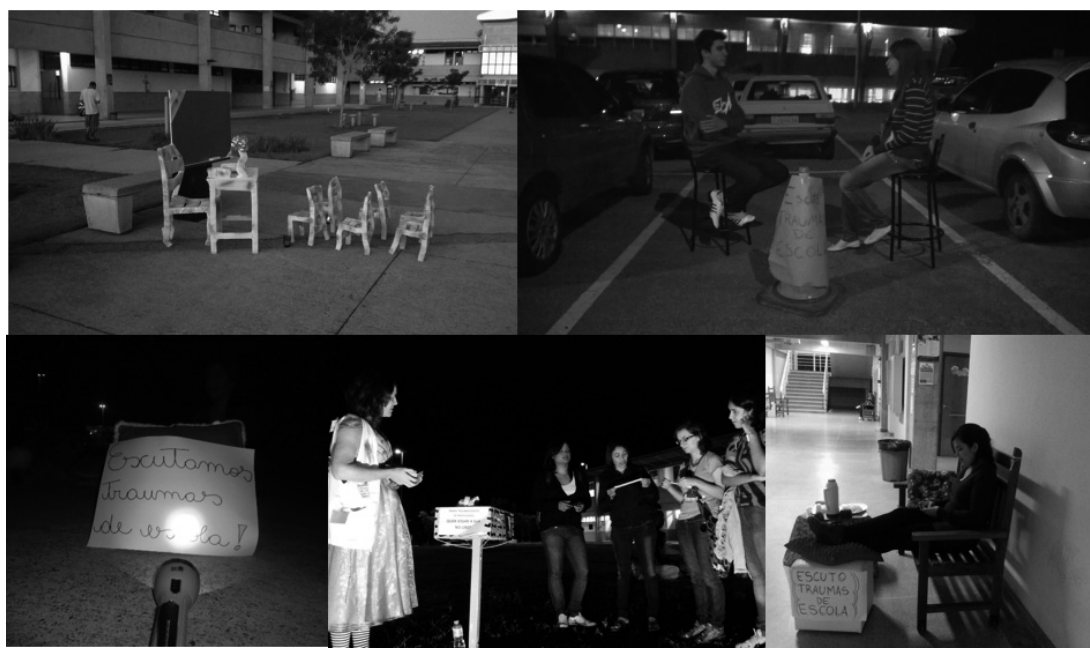

FONTE: Fotos dos acervos da autora e da estudante Anie Elisa de Moraes Fortes Tavares.

No gramado entre os prédios de laboratórios didáticos e de aulas teóricas, no estacionamento, nos corredores de um dos prédios de salas de aula, no ponto de ônibus e na lanchonete. As performances "Fraturas", do artista Ernesto Ferro em composição comigo e "Escuto Traumas de Escola" aconteceram durante uma tarde e uma noite de abril de 2014. Em visita à galeria de arte do artista Ernesto Ferro em Sorocaba, conhecemos sua obra "Fraturas", feitas em um processo criativo dele bastante complexo, que envolve a construção e destruição de cadeiras de madeira, que ele "cura" com gases a cada vez que as joga do alto do prédio, dando a elas outras identidades, fraturadas. Elas são instaladas em diferentes lugares da cidade. Convidamos o artista a intervir no campus universitário, para o que ele produziu uma nova série de peças fraturadas, em forma de "professora e estudantes" (na sala de aula retratada na imagem anterior). Nas proximidades dessa instalação, eu me vesti de professora-princesa e produzi um "realixo", isto é, uma lixeira pintada de amarelo como os antigos realejos, com a música típica daquela peça tocando intermitentemente e eu, recolhendo, de quem quisesse jogar no "realixo", frases traumatizantes de professores, contanto que fossem reais. Tempos antes, em outras oportunidades, já tendo recebido frases de outras pessoas, eu também oferecia uma frase para ser lida pelos transeuntes, assim como fazia o papagaio que "trabalhava" no velho realejo. Ao mesmo tempo, 
espalhados pelos espaços da universidade, estudantes da turma de "Metodologia e Prática do Ensino de Arte", oferecida no sétimo semestre do curso de Pedagogia, estavam abraçando a tarefa de escutar. O convite aos passantes era ser uma escuta dos traumas de escola que pudessem ter sofrido. Cada professor(a)-artista escolheu como seria seu cenário de escuta e onde seria montado. $\mathrm{Na}$ foto anterior se observa um estudante ocupando uma vaga do estacionamento, duas outras que se instalaram com lanternas no chão de uma passagem de pedestres, outra que montou uma sala de estar no saguão do prédio de aulas. A ideia dessa intervenção nasceu da apreciação do projeto da artista plástica Ana Teixeira chamado "Escuto Histórias de Amor." É uma ação de rua na qual Ana senta-se numa cadeira e põe outra ao seu lado. Enquanto espera que alguém que esteja passando sente-se e conte espontaneamente sua história, a artista tricota uma peça vermelha. Após a finalização das intervenções, tivemos uma conversa com o artista convidado, contextualizando e debatendo os temas.

Barbara Ginna, estudante do curso de Pedagogia, na ocasião das situações aqui relembradas, é hoje já formada e trabalha como professora de Educação Infantil. Ela envia seus pensamentos, especialmente para a construção deste artigo:

As ações performativas me proporcionaram reflexões antes, durante e após realizá-las. Foi algo que marcou a minha formação. Lembro-me das sensações e das surpresas que cada uma delas me proporcionaram, acredito que qualquer indivíduo que esteja envolvido na área da educação ou em contextos no qual existam as relações de ensino-aprendizagem deve participar de performances. Nas duas performances que realizei pude perceber claramente as relações de poder existentes na escola e que essas relações refletem fora da mesma com uma intensidade e reverberação maior do que se imagina. Senti na pele, através da exposição, o quanto o corpo é reprimido; desde um olhar, um gesto, um incomodo, uma reprovação e até em alguns casos com palavras duras e iradas. Me fez lembrar de situações que vivi na escola enquanto aluna, do corpo desde pequena sendo domesticado para se "adaptar" ao contexto social. Eu sempre me senti fora do contexto, nunca me encaixei em algum padrão, sempre destoava e na escola isso era potencializado negativamente. Os professores não tinham preparo para lidar comigo e sempre ouvi coisas como: "Não tem um botão onde desliga? Nossa! Você não para? Você não cansa não? Você é ligada no 220 volts!". Nas performances pude perceber e entender o que antes quando era uma criança não conseguia entender. Entendi que as repressões vão muito além da escola, que o diferente, o incompreendido será reprimido, por medo, desconforto, por estar fora do padrão, mas que na verdade isso é um pedido de socorro de alguém que um dia também foi reprimido e não percebeu o que isso 
Ihe causou, e que ainda está preso nessas ações, sem reflexão. Pensamos que por estar na Universidade estamos livres de passar por algumas situações, acreditamos que as pessoas que ali se encontram já estão mais maduras e prontas para lidar com diversas situações, contudo foi nessa que me enganei, ao ser exposta nas performances vi o quanto as pessoas se vestem com a capa e a máscara que a Universidade requer, mas se pressionados sedem e agem com seus instintos mais ignorantes e deixam florescer seus escárnios. Participar de ações performativas me proporcionou um novo olhar, um novo sentir, um novo agir. Resgatou o que tenho de mais inocente e belo em meu interior. ${ }^{2}$

\section{"Menin@s"}

FIGURA 3: IMAGENS DA PERFORMANCE “MENIN@S”.

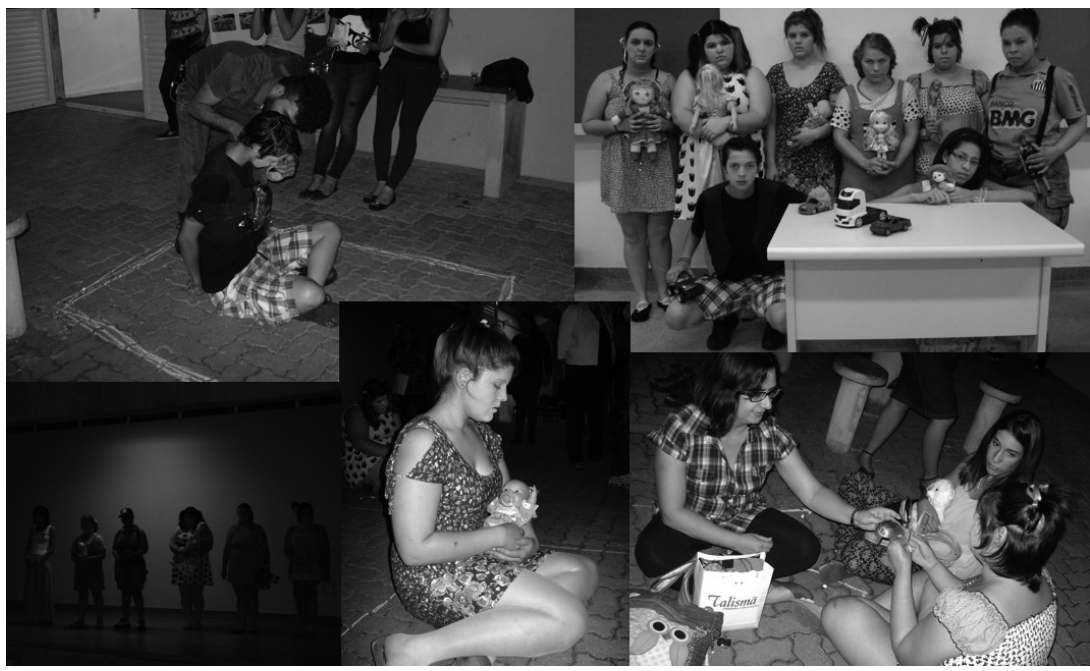

FONTE: Fotos do acervo da autora

Novamente um contexto de minicurso de cinco noites, em um evento científico do curso de Pedagogia, oferece lugar para a realização das etapas de trabalho descritas anteriormente no texto, que envolvem processos do ensino da arte de fazer, fruir e contextualizar na arte da performance, já que apesar de se tratar de processos de criação com a arte da performance, minhas responsabilidades como arte/educadora, mediadora em ações que são modificadoras

2 Barbara Ginna. Informação pessoal recebida por e-mail. Autorizada em seu uso por meio de assinatura de Consentimento Informado e Esclarecido. 
do conhecimento e não simplesmente meios de comunicação (ZUMTHOR, 2014), permanecem. "MENIN@S” surgiu do desejo das estudantes de discutir as questões de orientação de gênero e de identidade de gênero em suas próprias vidas, como também na Educação Infantil. Elas invadiram o espaço urbano caracterizando-se como crianças, de posse de identidades herméticas, marcadas pelo aprisionamento em um único brinquedo possível e um único espaço que poderia ser ocupado (desenhado por elas mesmas no chão, com riscos feitos de giz). Naquela ocasião as respostas do público foram muito fortes, com interações incisivas e invasivas. Imaginamos que isto tenha ocorrido porque se tratavam de "crianças". Há certas visões do universo adulto de que a criança pode ser naturalmente submetida. A estudante Thayne dos Santos Rosa, escreveu após sua experiência de performar em "MENIN@S" e de realizar a leitura de Alice (2013):

$O$ interessante da performance é que com ela pessoas que não são escutadas, ou não podem ir até lugares ditos como artísticos podem participar. A função ecológica social da performance pretende o trabalho com as relações humanas em todas suas vertentes e insiste na resistência a práticas padronizadas pela sociedade capitalista. Há a possibilidade de categorizar então algo tão íntimo como a performance? Penso que não, pela abertura que essa linguagem nos oferece, nos transmite e as possibilidades de troca, de complementação por meio das relações humanas, um dispositivo de luta e resistência, uma forma de levar para todos os espaços sua visão de mundo, perante a vida, perante a conjuntura. A performance não pode ser determinada, não há um jeito certo, mas evidentemente a única certeza é que ela pode significar o que quisermos, não se importa com o significado da obra, mas sim com o que acontece no momento, no instante e naquele lugar, o que entender, vai depender de você mesmo, de sua bagagem social e cultural. ${ }^{3}$

Calíope Oliveira Corcovia, estudante do curso de Pedagogia, escreveu suas ideias:

Primeiro de tudo, achei bem engraçado todo o "preparo sério" que tivemos. O juntar todo mundo para idealizar a intervenção, planejar nossas

3 Thayne dos Santos Rosa e Calíope Oliveira Corcovia. Informações pessoais recebidas por e-mail. Autorizadas em seu uso por meio de assinaturas de Consentimento Informado e Esclarecido. 
ações e fazer alguns combinados, era uma coisa que eu não imaginava existir e sequer imaginava necessária. Pensar em uma atividade performática sem nunca ter realizado uma faz parecer tudo muito espontâneo a ponto de não parecer organizado. Fiquei me perguntando, depois, se faria sentido esse planejamento, se ele não mataria a "arte" da coisa. [...] Durante a performance eu vi a imprevisibilidade "comendo" nossos planos. As pessoas passam e interagem diferente do esperado. Mesmo que você se prepare pra tudo e mais um pouco, ainda vai aparecer alguém pra "causar", fazendo uma coisa que ninguém tinha pensado que poderia acontecer. No nosso caso, éramos crianças fúnebres presas com nossos brinquedos designados a nós pelo nosso sexo biológico (brinquedos "de menino $X$ de menina") e um cara chegou com um rolo de fita adesiva prendendo a gente mais ainda. Quando isso aconteceu eu não sabia o que fazer, eu não conseguia imaginar um motivo pra ele fazer isso e fiquei tentando entender o que aquilo poderia estar significando pra ele. Não fez sentido na minha cabeça até hoje pra falar a verdade. Eu acho que a dúvida também é aprendizado, especialmente na arte. Porque a dúvida da arte, de quando você acha que não entendeu um quadro, de quando você não vê sentido em uma escultura, de quando você acha que qualquer coisa artística é "sem propósito" é uma dúvida que já te mudou: mesmo sem ver o sentido da coisa, você já viu a coisa, e isso é algo a mais na sua experiência. Talvez aquilo vá te impactar de fato muito tempo depois, quando você já conhecer outras coisas que ajudem a atribuir um sentido pr'aquilo. Eu acho que uma das coisas mais legais da performance é como ela envolve pessoas de verdade interagindo de verdade e geralmente fazendo coisas e criando situações incomuns. Ela tem mais facilidade de despertar sentimentos.

\section{Considerações finais}

"Cada performance nova coloca tudo em causa." Paul Zumthor (2014, p. 36)

O texto procura descrever procedimentos, refletindo sobre seus processos e alguns de seus resultados, porque partilhar culturas praxiológicas que desenvolvem gramáticas do fazer pedagógico pode estabelecer diálogos entre profissionais que enfrentam desafios similares e, quando realizada em uma perspectiva de reconhecimento da pluralidade das epistemologias da prática, representa o melhor uso da memória pedagógica para a reconstrução de cotidianos que promovam a participação (OLIVEIRA-FORMOSINHO, 2007). 
Ações potentes de deslocar as formas cristalizadas de ser professor, de ser aluno, de se estabelecer relações na sala de aula; de descompor os corpos contagiados (que adquiriram e que transmitem) por opressões e disciplinamentos; de desalojar as forças políticas, ideológicas e pedagógicas enraizadas na escola, interessam nos processos contemporâneos de formação de professores porque alguns de nós temos desejo por uma mudança dos paradigmas que pautam o sistema educacional.

A arte da performance aparece, no caso da formação de pedagogos, como acontecimento que provoca discussão sobre valores e hábitos, que promove a experimentação de relações não hierárquicas, a exploração de limites, o mergulho em incertezas, a quebra de convenções. Realizando e efetuando-se, de acordo com Alice (2013), a linguagem da performance desfaz a lógica de sistemas imediatamente decifráveis e interpretáveis, propõe transformações nos modelos de poder vigente, remodelando as subjetividades e as relações previamente estabelecidas. Ainda, propõe alternativas para a transformação.

Interessam a relação democrática que é estabelecida entre quem atua e quem passa e os espaços de liberdade deixados na intervenção em si mesma, que não apresentam tudo acabado, mas sim, deixam lacunas a serem preenchidas de significados.

Vivemos hoje, intensamente, as contradições entre a necessidade de ordenar, classificar, padronizar, que são parte de um ideário que costuma ser vinculado ao ofício do professor e a busca por incertezas, deslocamentos, desconstrução de padrões, ideário que costuma ser vinculado ao trabalho do artista da performance. Por esse viés, educar e performar se apresentariam como atividades quase que diametralmente opostas. Mas por isso mesmo, o choque entre as normatizações da instituição escolar e a prática artística da performance parecem fazer emergir uma reflexão crítica frutífera sobre o funcionamento do sistema sócio-político-econômico ao qual estamos submetidos (RACHEL, 2013). E nosso projeto estético não poderia deixar de enfrentar essas questões.

\section{REFERÊNCIAS}

ALICE, T. Diluição das fronteiras entre linguagens artísticas: a performance como (r)evolução dos afetos. Palco Giratório: circuito nacional. Rio de Janeiro: SESC, Departamento Nacional, 2013, p. 32- 43.

COHEN, R. Performance como linguagem: criação de um tempo-espaço de experimentação. São Paulo: Perspectiva, 2002. 
FABIÃO, E. Performance e Teatro: poéticas e políticas da cena contemporânea. Sala Preta, Brasil, v. 8, nov. 2008, p. 235-246.

LOMBARDI, L. M. S. S. Formação corporal de professoras de bebês: contribuições da Pedagogia do Teatro. Tese (Doutorado em Educação). Faculdade de Educação, Universidade de São Paulo, São Paulo, 2011.

LOMBARDI, L. M. S. S. Sobre o teatro no curso de Pedagogia. Trama Interdisciplinar, São Paulo, v. 6, n. 2, maio/ago. 2015, p. 116-129.

LOMBARDI, L. M. S. S. Formação corporal de pedagogos e Pedagogia do Teatro...meu caminho sou eu quem faço. In: TODARO, M. de Á.; FABRIN, F.; NÒBREGA, M. L. S. de. (Org.). Corpo e educação: desafios e possibilidades. São Paulo: Paco Editorial, 2015 a, v. 1, p. 44-63.

NARDIM, T. L. Programas performativos e agenciamentos didáticos na instituição escolar ou Empunhar a professoralidade e fazê-la vibrar. Linha Mestra (Associação de Leitura do Brasil), v. 27, p. 277-279, 2015.

NARDIM, T. L. Performances e pedagogias: arte contemporânea e aprendizagens, na escola e fora dela. Saarbrücken: Novas Edições Acadêmicas, 2015 a.

NARDIM, T. L. Levar a arte da performance da licenciatura em teatro ao chão da escola - e friccioná-los todos. In: SILVA, S. A. da; SILVA, S. C. da. (Org.). Arte e docência. 1. ed. Fortaleza: Editora do Instituto Federal do Ceará (IFCE), 2015 b, v. 1, p. 361-372.

NARDIM, T. L. Professor-performer: didática menor para o letramento performativo. Linha Mestra (Associação de Leitura do Brasil), v. 24, p. 3.234-3.237, 2014.

NARDIM, T. L. Três esboços para horizontes imprecisos: lentes de Allan Kaprow para pensar a performance hoje. Conceição/Conception - Revista do Programa de Pós-Graduação em Artes da Cena, v. 1, p. 87-98, 2013.

OLIVEIRA-FORMOSINHO, J.; Pedagogia(s) da infância: reconstruindo uma práxis de participação. In: OLIVEIRA-FORMOSINHO, J; KISHIMOTO, T. M.; PINAZZA, M. A. (Org.). Pedagogia(s) da infância: dialogando com o passado - construindo o futuro. Porto Alegre: Artmed, 2007. p. 13-36.

PARO, V. H. Implicações do caráter político da educação para a administração da escola pública. Educação e Pesquisa, São Paulo, v. 28, n.2, jul./dez. 2002, p. 11-23.

PEREIRA, M. de A. (Org.). Performance e educação: [des]territorializações pedagógicas. Santa Maria: Editora da UFSM, 2013.

PEREIRA, M. de A. Pedagogia da Performance: do uso poético da palavra na prática educativa. Educação \& Realidade, v. 35, n. 2, maio-ago., 2010, p. 139-156.

PINEAU, E. L. Nos cruzamentos entre a performance e a pedagogia: uma revisão prospectiva. Revista Educação \& Realidade, Porto Alegre, v. 35, n. 2, p. 89-113, maio/ago. 2010. 
RACHEL, D. P. Adote o artista não deixe ele virar professor: reflexões em torno do híbrido professor performer. Dissertação (Mestrado em Artes) - Universidade Estadual Paulista, Instituto de Artes, São Paulo, 2013.

ZUMTHOR, P. Performance, recepção, leitura. São Paulo: Cosac Naify, 2014.

Texto recebido em 29 de outubro de 2017. Texto aprovado em 31 de outubro de 2017. 
